\title{
PACTO FEDERATIVO BRASILEIRO: DESAFIOS NA CONTEMPORANEIDADE
}

\section{BRAZILIAN FEDERAL PACT: CHALLENGES IN THE CONTEMPORARY WORLD}

\author{
Guilherme Sandoval Góes ${ }^{i}$ \\ Cleyson de Moraes Melloii
}

Resumo: O estudo do pacto federativo perpassa por um espectro multidimensional da organização político-social do Estado Democrático de Direito que envolve a repartição constitucional de competências, a separação vertical de poderes, a regra democrática e a proteção de direitos fundamentais. A partir de assimilação acrítica do federalismo centrípeto norte-americano, o pacto federativo brasileiro gestou graves distorções que são perceptíveis até os dias de hoje, daí a necessidade de reestruturá -lo com a finalidade de promover a redução das desigualdades regionais e potencializar o desenvolvimento nacional. Com efeito, urge reconfigurar o pacto brasileiro a partir de alterações normativas capazes de reduzir o gigantismo centralizador da União, em detrimento dos Estados-membros, fortalecendo mecanismos de desenvolvimento estratégico do Brasil.

Palavras-chave: Federalismo centrífugo. Geodireito. Federalismo centrípeto. Reconfiguração do pacto federativo.

i Pós-doutorando em Geopolítica, Cultura e Direito pela Universidade da Força Aérea (UNIFA). Doutor em Direito Internacional e da Integração Econômica pela Universidade do Estado do Rio de Janeiro (UERJ). Mestre em Direito Público pela Universidade do Estado do Rio de Janeiro (UERJ). Professor Emérito da Escola de Comando e Estado-Maior do Exército (ECEME).

ii Professor Adjunto da Faculdade de Direito da UERJ. Departamento de Teorias e Fundamento do Direito. Diretor Adjunto da Faculdade de Direito de Valença - RJ; Professor Titular da Universidade Estácio de Sá - Rio de Janeiro - Brasil; Doutor e Mestre em Direito. profcleysonmello@hotmail.com. 
Abstract: The study of the federative pact runs through a multidimensional spectrum of the political-social organization of Rule of Law, which involves the constitutional division of responsabilities, vertical separation of powers, democratic rule and protection of fundamental rights. From the uncritical assimilation of US centripetal federalism, the Brazilian federal pact has created serious distortions that are perceptible to the present day, hence the need to restructure it with the purpose of promoting the reduction of regional inequalities and enhancing national development. Indeed, it is urgent to reconfigure the Brazilian pact through normative changes capable of reducing the Union's centralizing gigantism to the detriment of subnational, strengthening Brazil's strategic development mechanisms.

Keywords: Centrifugal Federalism. Centripetal federalism. Reconfiguration of the federative agreement pact.

\section{INTRODUÇÃo}

O estudo do pacto federativo é um dos temas mais fascinantes da teoria constitucional, uma vez que abarca um espectro epistemológico multidimensional que mescla, dentre outros, os conceitos de Estado Democrático de Direito, repartição constitucional de competências, autonomia dos entes federativos, separação vertical de poderes e desenvolvimento nacional.

Dessarte, a análise do princípio federativo não pode mais se limitar ao debate em torno da organização político-administrativa do Estado vislumbrada como um pacto de cooperação de Estados que abrem mão de sua soberania em prol da formação de um único Estado federal.

É nesse diapasão que o presente trabalho tem a finalidade de fixar o núcleo essencial do princípio federativo, enquanto cláusula pétrea, de modo a delinear seu conteúdo jurídico mínimo, sem o qual o pacto federal ficaria esvaziado sem nenhuma efetividade. Isto significa dizer que o pacto federativo brasileiro ainda se encontra em construção, carecendo de maior desenvolvimento científico, seja na esfera da teoria constitucional, seja na esfera da ciência política. Nesse sentido, Gilmar Mendes alerta que:

"Os princípios merecedores de proteção, tal como enunciados normalmente nas chamadas cláusulas pétreas, pa- 
recem despidos de conteúdo específico. O que significa, efetivamente, separação de Poderes ou forma federativa? O que é um Estado de Direito Democrático? Qual o significado da proteção da dignidade humana? Qual a dimensão do princípio federativo ${ }^{1 "}$ ?

Em consequência, a doutrina pátria ganha a missão de edificar as bases epistemológicas do conteúdo jurídico mínimo do princípio federativo, ou seja, estabelecer um minimum normativo que fixe os limites da atuação dos entes federativos a partir de relações constitucionalmente garantidas entre a União, os estados-membros, o Distrito Federal e os municípios. Com isso, aspira-se contribuir para a abertura de novos espaços de reflexão científica dentro da teoria constitucional, fazendo-a estabelecer a fronteira jurídico-constitucional da cláusula de eternidade da forma federativa do Estado brasileiro.

Por conseguinte, em um primeiro momento, este artigo tem a pretensão de examinar a formação do pacto federativo, que surgiu a partir da declaração de independência das treze ex-colônias britânicas, que se estruturaram numa entidade até então inexistente, com o desiderato de obter maior segurança contra ameaças externas e internas. No plano teórico-conceitual, a formação do pacto federal norte-americano nasceu juntamente com o conceito de presidencialismo em contraposição ao parlamentarismo, sistema de governo até então dominante na Europa.

Assim, pode-se afirmar que a declaração de independência dos EUA marca, a um só tempo, a criação de uma nova forma de Estado (federação) e de um novo sistema de governo (presidencialismo). Além disso, é importante compreender que a formação do pacto federativo estadunidense projeta a ideia de que a organização do poder político no espaço ocorreu através de força centrípeta, isto é, de fora para o centro, por agregação, partindo-se de uma Confederação de estados soberanos para uma Federação de estados meramente autônomos. Isto justifica o atual paradigma federal dos EUA, no qual os estados-membros (verdadeiramente soberanos na condição anterior de Confederação) possuem alto grau autonômico em termos de repartição constitucional de competências, bem como de autonomia financeira e fiscal em relação à União.

1 Disponível em: <https://nacoesunidas.org/wp-content/uploads/2015/10/agenda2030-pt-br.pdf> Acesso em: 4 fev. 2018. 
Já o pacto federativo brasileiro nasceu a partir de uma força centrífuga, isto é, do centro para fora, por desagregação, partindo-se de um Estado Unitário Absoluto para um Estado Federal. Isto significa dizer que, diferentemente do modelo norte-americano, a federação brasileira apresenta uma estrutura na qual, muito embora não exista hierarquia formal entre as unidades federadas, existe, sim, uma predominância cêntrica do poder central (União) em termos de repartição de competências, arrecadação de impostos e níveis de formulação de políticas públicas, daí surgindo a imagem de Estado Federal Fictício ou de Estado Unitário de Fato.

Eis aqui a primeira linha de investigação do presente artigo, qual seja examinar as distorções do atual pacto federativo brasileiro, cujo modelo centrífugo de formação contribui para o empoderamento do ente central em detrimento dos governos subnacionais.

Fácil é perceber, pois, que a assimilação acrítica do modelo estadunidense gerou entre nós uma forma fictícia de Estado Federal, que manteve um processo decisório centralizado, no qual o poder central é o difusor das grandes políticas públicas do País e principal coletor de taxas e impostos. É nesse sentido que surgem as grandes distorções do federalismo centrífugo brasileiro, que, aliás, persistem até os dias de hoje: grande concentração de competências enumeradas da União; alta dependência das entidades federativas - notadamente dos municípios - às transferências e repasses tributários obrigatórios feitos pela União e baixo grau de autonomia dos governos subnacionais.

Já a segunda linha epistemológica aspira traçar as bases teóricas que informam a criação do assim chamado federalismo tridimensional brasileiro, modelo único na teoria constitucional contemporânea, na medida em que consagra o poder municipal como ente federativo, juntamente com os Estados, o Distrito Federal e a União.

Portanto, é nesta segunda segmentação temática que se examinará a elevação do município ao patamar de entidade político-administrativa com personalidade jurídica de Direito Público, dotada de autonomia e competência normativa constitucionalmente estabelecida. Assim, destacando essa característica originária do Direito Brasileiro, Augusto Zimmermann mostra que:

"A recepção do município como membro federativo é uma heterodoxia deveras peculiar à organização federativa brasileira. Tradicionalmente, o Estado Federal promove apenas um sistema bipartido ou bidimensional, porquan- 
to os únicos entes federativos que costumem figurar nas constituições federais sejam a União e os estados-membros." (ZIMMERMANN, 2005, p. 46).

Ainda dentro dessa segunda segmentação temática, a intenção é examinar a valorização política da esfera municipal dentro da reestruturação do pacto federativo feita pela Constituição de 1988. Em consequência, a ideia é perscrutar questões tais como clientelismo e populismo na órbita municipal, distorções no sistema constitucional de repartição de competências das unidades subnacionais e desvios nos sistemas de representação política. Com isso, desponta a necessidade de reestruturar o pacto federativo brasileiro, cujo modelo centrífugo acabou por gestar graves distorções, que, em última instância, nada mais fazem do que agravar o ciclo do empobrecimento estatal, aumentar as desigualdades regionais e sociais e potencializar os desvios dos sistemas de representação política.

Finalmente, o terceiro momento de análise do presente artigo pretende percorrer a senda das teorias do núcleo essencial e, em especial, o exame do conteúdo jurídico mínimo do princípio federativo. Por sua maior complexidade, ênfase será dada ao estudo da doutrina e da jurisprudência pátrias, na tentativa de estabelecer um primeiro esboço hermenêutico daquilo que poderia constituir o núcleo essencial da forma federativa de Estado.

Para perquirir a natureza jurídica de tal núcleo essencial com a devida densidade acadêmica, é preciso antes investigar o caráter multifacetado, que abarca diferentes aspectos da organização político-social do Estado contemporâneo, tais como perscrutação do grau de autonomia das unidades federadas, boa ou má repartição constitucional de competências, efetiva distribuição igualitária de justiça e, finalmente, o grau de proteção dos direitos fundamentais proporcionado pela adequada organização do poder político no espaço.

\section{ADVENTO DO ESTADO FEDERAL NORTE-AMERICANO E SUA INFLUÊNCIA NO DIREITO BRASILEIRO}

O processo de formação centrípeta do Estado Federal Norte-Americano começou em 1775 - ocasião da revolta dos colonos contra as políticas financeiras do Reino Unido, sob o comando de Jorge III - e terminou em 1787 com a Convenção da Filadélfia, cujo desfecho foi a promulgação da Constituição dos Estados Unidos da América do Norte. 
Assim sendo, a declaração de independência da Virginia de 1776, redigida e assinada por uma comissão de cinco membros comandada por Thomas Jefferson, transformou as treze colônias em Estados livres do jugo britânico, imprimindo-Ihes o caráter jurídico de Estados soberanos e atribuindo-Ihes a capacidade de formular sua própria legislação e organização político-administrativa.

Já no Brasil, como visto, antes mesmo de nossa primeira Constituição republicana, o artigo inaugural do Decreto nº 1 de 1889 já estabelecia oficialmente que o Brasil seria uma República Federativa, cujas Províncias reunidas pelo laço da federação formariam os Estados Unidos do Brasil (art. $2^{\circ}$ do Decreto ut supra). ${ }^{2}$ Há de se observar, portanto, que, ao contrário do que ocorreu nos EUA, onde o processo de elaboração do pacto federativo foi sendo lapidado paulatinamente, no Brasil, o princípio federativo foi importado e imposto a uma realidade de estatalidade unitária que certamente ainda não estava preparada para absorvê-lo.

Na verdade, a questão não é tão somente acerca da condição anterior de estatalidade unitária do Estado Brasileiro, mas, principalmente, do tipo de federalismo importado e que foi o federalismo dual, cuja principal característica é a busca de equilíbrio entre a União e os Estadosmembros, não havendo relação de subordinação entre ambos.

E assim é que o modelo brasileiro, ao incorporar acriticamente os elementos centrais do federalismo dual norte-americano, estabeleceu rigorosa igualdade jurídica entre os Estados-membros e a União, afastando destarte qualquer perspectiva de interferência da União no quadro geral de competências constitucionalmente asseguradas às entidades federadas subnacionais. Nesse diapasão, não vislumbraram os sectários brasileiros do modelo norte-americano diversos fatos característicos do Brasil Império, paradigma estatal preexistente, e, em especial, o desnível de desenvolvimento entre as antigas Províncias, transformadas literalmente

\footnotetext{
2 Todavia, sustenta Paulo Bonavides ser "errôneo supor que a Federação no Brasil foi produzida unicamente pelo Decreto $n^{\circ} 1$, do Governo provisório de 1889 . Se o presidencialismo colhe de surpresa o País, desconhecido que era a todas as tradições de embate doutrinário em que nos havíamos empenhado durante a fase anterior à República, tal não se deu, porém, com a Federação. Esta, ou já se desejava, no sentir de monarquistas abalizados, da índole liberal de Nabuco e Rui, ou já aguardava, por solução lógica e idônea aos antagonismos e crises que desde muito dilaceravam o corpo político da Monarquia. O Decreto 1 foi apenas o coroamento vitorioso de velhas aspirações autonomistas que, não se podendo fazer nos quadros institucionais do Império por um ato reformista, se fizeram via improvisação da ação revolucionária de 15 de novembro de 1889, resultando, assim, na implantação do sistema republicano". (BONAVIDES, 1996, p. 390, apud VON RONDOW, 2002).
} 
da noite para o dia em Estados-membros dotados de igual capacidade jurídica do poder central.

Em suma, de toda esta análise até aqui desenvolvida, resta indubitável que o processo de assimilação acrítica do federalismo centrípeto norte-americano gerou grandes distorções no Direito pátrio, tais como: grande concentração de competências enumeradas da União; grande dependência dos governos subnacionais - notadamente os municípios - das transferências e repasses tributários obrigatórios feitos pela União, uma vez que a maior parte da arrecadação de tributos no Brasil se concentra na órbita da União; baixo grau de autonomia dos governos subnacionais (estados e municípios), em especial, a autonomia legislativa e tributária e criação ilusória de um Estado Federal brasileiro, que, na opinião de grandes publicistas, em última instância, é mera ficção jurídica, na medida em que se institucionalizou o gigantismo centralizador da União em detrimento dos Estados-membros.

É por isso que Paulo Bonavides postula a criação de um novo modelo federalista para o Brasil, o federalismo das Regiões, cujo objetivo é neutralizar a tendência cada vez maior de Estados Federais monolíticos, verdadeiros estados unitários que não deixam margem de manobra para as unidades subnacionais.

Com efeito, não se pode negar a tendência brasileira centralizadora que se consubstancia na área de competência da União que é amplíssima, na medida em que a competência residual dos Estados - prevista no artigo $25, \S 1^{\circ}$, da Constituição Federal - é bastante mitigada ante o rol extenso de competências enumeradas da União, previstas no artigo 21 (competência exclusiva) e no artigo 22 (competência privativa).

É de se observar, portanto, que a competência residual dos Estados-membros foi coarctada por dispositivos constitucionais, que agigantaram as prerrogativas e competências do poder central (União), reservando-Ihe indubitavelmente aquelas de maior importância.

À guisa de conclusão desse segmento temático, impende, pois, compilar, em quadro teórico-conceitual, o modelo estadunidense que, como visto exaustivamente, é muito diferente do brasileiro. Assim, é importante destacar as bases teóricas que explicam o alto grau de autonomia dos governos subnacionais dos Estados Unidos quando comparados com seus congêneres do Brasil:

a) a formação do federalismo norte-americano foi centrípeta, isto é, ocorreu da passagem de um Estado Confederal para um Estado Federal, 
enquanto que o federalismo brasileiro é centrífugo, ou seja, ocorreu da passagem de um Estado Unitário para um Estado Federal, o que explica até hoje a maior autonomia dos estados estadunidenses quando comparados com os brasileiros;

b) os governos subnacionais norte-americanos podem estabelecer a forma unicameral ou bicameral para o poder constituinte derivado decorrente (poder legislativo dos estados-membros); já os estados brasileiros adotam necessariamente a forma unicameral;

c) os entes federativos estadunidenses possuem ampla discricionariedade para legislar sobre Direito Civil, Comercial, Processual, Eleitoral, Penal e outros, sendo mesmo possível que alguns estados da Federação norte-americana adotem a pena de morte e outros não, ou, que alguns adotem o divórcio e outros não, enquanto que, no Brasil, tais matérias são de competência privativa da União;

d) os estados-membros da Federação norte-americana não ficam submetidos aos rigores do princípio da simetria, na medida em que gozam de livre arbítrio quanto às linhas gerais do sistema presidencialista e quanto aos sistemas de organização e governo municipais;

e) os governos subnacionais estadunidenses possuem plena autonomia na estruturação do seu sistema judiciário e do seu sistema eleitoral, podendo até mesmo chegar a adotar institutos de democracia plebiscitária rousseauniana, como por exemplo o referendum (consulta popular de convalidação) ou o recall (revogação do mandato eletivo por infidelidade às teses programáticas mediante manifestação superveniente do eleitorado);

f) as unidades federativas locais dispõem de grande poder de veto no processo de atualização do Estado Federal norte-americano, na medida em que a aprovação de emendas constitucionais, mesmo que não afetem a distribuição federal de poderes, exigem a ratificação de três quartos dos estados-membros, sendo que há tipos de emendas à Constituição que não podem ser aprovadas sem a ratificação de 49 dos 50 estadosmembros da Federação Norte-Americana.

Em suma, a compilação do quadro teórico-conceitual da estrutura federal brasileira permite projetar a perpetuação do gigantismo jurídico-financeiro da União, cujo desfecho é melancólico: aumento das desigualdades regionais e das desigualdades sociais, na contramão do que estabelece um dos objetivos fundamentais do Estado Brasileiro. 


\section{BASES TEÓRICAS DO FEDERALISMO TRIDIMENSIONAL BRASILEIRO}

Pelas dimensões continentais do território nacional, pelas suas disparidades socioeconômicas, sejam inter-regionais, sejam interpessoais, pela sua diversidade geográfica e pela sua estatura geopolítica, o Brasil carece urgentemente de perspectiva de desenvolvimento estratégico, cuja articulação perpassa, necessariamente, pelo aperfeiçoamento do pacto federativo, e, em especial, pela cooperação das entidades federadas e o poder central.

A Constituição de 1988 introduziu mudanças significativas na Federação brasileira atinentes à descentralização do poder político e financeiro para as esferas subnacionais. Um dos principais objetivos da Assembleia Nacional Constituinte foi reestruturar o sistema federal pátrio, tentando imprimir-lhe maior descentralização e equilíbrio entre os entes federativos e transformando o princípio federativo em cláusula pétrea.

Além disso, a Constituição de 1988 instaurou uma nova era do pacto federal brasileiro, tornando-o tridimensional, ao erigir o município em ente federativo autônomo. Nesse sentido, o entendimento pretoriano do eminente Ministro Celso de Mello que assim se manifestou acerca da autonomia municipal, verbis:

"(...) Cabe assinalar, neste ponto, que a autonomia municipal erige-se à condição de princípio estruturante da organização institucional do Estado Brasileiro, qualificando-se como prerrogativa política, que, outorgada ao município pela própria Constituição da República, somente por esta pode ser validamente limitada. ${ }^{3 "}$

No entanto, a aceitação da ideia de que o município é um ente federativo ainda encontra resistência na doutrina. A juíza Lia Sammia Souza Moreira, em lapidar trabalho monográfico apresentado à Escola Superior de Guerra para a obtenção do diploma do Curso de Altos Estudos de Política e Estratégia, preleciona que:

"A Constituição Federal de 1988 inaugura uma fase inovadora do municipalismo e do federalismo brasileiros. Sem parâmetros em outros países, a nova Carta Magna eleva o

3 RE 251542/SP. Min. Rel. Celso de Mello. Informativo STF nº 394. 
município à condição de ente da federação, isto é, membro do pacto federativo ao lado dos estados." (MOREIRA, 2002, p. 49) ${ }^{4}$

Nesse ponto da análise, é importante compreender que o conceito de Federalismo enquanto forma de Estado é muito mais amplo que o vetusto entendimento de que o Estado Federal é a união de estados autônomos. Com certeza não existe uma Federação de Municípios, porém, a autonomia municipal foi erigida à categoria de princípio estruturante da organização institucional do Estado Brasileiro (Min. Celso de Mello).

Para além disso, a autonomia municipal foi inserida no rol de princípios constitucionais sensíveis, cuja violação pelo estado-membro autoriza a intervenção federal nos termos do artigo 34, inciso VII, alínea "c" da Constituição.

Nem mesmo certas restrições constitucionais impostas aos municípios, e.g., não possuírem poder judiciário, estarem proibidos de constituir tribunais de conta e não terem representação junto à União, isto é, não participarem na formação da vontade nacional, retiram-lhes a condição de membro do pacto federativo brasileiro.

Acrescente-se ainda que os municípios foram aquinhoados, no que tange à repartição horizontal de competências, com a capacidade para legislar sobre assunto de interesse local (art. 30, inciso I), bem como, no plano da repartição vertical de competências, a suplementar a legislação federal e a estadual no que couber (art. 30, inciso II) e a competência administrativa comum envolvendo as três esferas de poder (art. 23).

\footnotetext{
4 Essa disposição constitucional não foi recebida com apreço pelo constitucionalista José Afonso da Silva que, sem se manifestar contra a autonomia municipal, não aceita a inclusão do município como ente federativo. Argumenta o Professor José Afonso que: "não é porque uma entidade territorial tenha autonomia político-constitucional que necessariamente integre o conceito de entidade federativa. Nem o município é essencial ao conceito de federação brasileira. Não existe federação de municípios. Existe federação de estados. Estes é que são essenciais ao conceito de qualquer federação. (...) Dizer que a República Federativa do Brasil é formada da união indissolúvel dos municípios é algo sem sentido, porque, se assim fora, ter-se-ia que admitir que a Constituição está provendo contra uma hipotética secessão municipal. Acontece que a sanção correspondente a tal hipótese é a intervenção federal que não existe em relação aos municípios. A intervenção neles é da competência dos estados, não da União. (...) Outro aspecto que mostra que os municípios continuam a ser divisões dos estados acha-se no fato de que sua criação, incorporação, fusão e desmembramento far-se-ão por lei estadual, segundo requisitos previstos em lei complementar também estadual (art.18, § $4^{\circ}$ ), e dependerão de plebiscito (que é sempre uma consulta prévia) das populações diretamente interessadas (...)". (SILVA, 1997, p. 451).
} 
De tudo se vê, por conseguinte, que, muito embora grande parte da doutrina constitucionalista pátria prefira a intelecção de que o município não pode ser considerado ente federativo, o fato é que os comandos constitucionais mostram com clareza meridiana que o pacto federativo brasileiro é tridimensional (União, estados-membros/Distrito Federal e municípios) e não mais bidimensional (União e estados-membros).

Uma vez caracterizada a autonomia municipal dentro de um federalismo tridimensional, importa, agora, examinar a fixação do núcleo essencial e as perspectivas de evolução do pacto federal brasileiro, que parte da doutrina entende claudicante, mas, que, na verdade, necessita apenas aperfeiçoar seus mecanismos de cooperação, com a respectiva valorização política da esfera municipal, dentro de um quadro geral mais amplo de arrecadação de recursos e encargos atinentes ao bem-estar social.

\section{A CONSTRUÇÃO DOGMÁTICA DO NÚCLEO ESSENCIAL DO PRINCÍPIO FEDERATIVO}

A nosso juízo, acreditamos que, muito embora já se tenham passados trinta anos da promulgação da Carta Constitucional de 1988, o conhecimento hermenêutico acumulado sobre o núcleo essencial dos direitos constitucionais e, em especial, das cláusulas pétreas ainda é controverso e insuficiente. A doutrina e a jurisprudência ainda não foram capazes de elaborar os conteúdos específicos dos comandos constitucionais gravados com o manto de imutabilidade. Nesse mister, precisa a lição de Gilmar Mendes:

"Essas assertivas têm a virtude de demonstrar que o efetivo conteúdo das 'garantias de eternidade' somente será obtido mediante esforço hermenêutico. Apenas essa atividade poderá revelar os princípios constitucionais que, ainda que não contemplados expressamente nas cláusulas pétreas, guardam estreita vinculação com os princípios por elas protegidos e estão, por isso, cobertos pela garantia de imutabilidade que delas dimana. (...) Essas indagações somente podem ser respondidas, adequadamente, no contexto de determinado sistema constitucional. É o exame sistemático das disposições constitucionais integrantes do modelo constitucional que permitirá explicitar o conteúdo de determinado princípio. ${ }^{. \prime}$

5 Cf. MC em ADPF 33-5 PARÁ. Min. Rel. Gilmar Mendes. DJU 20/03/2003, p. 7-8. 
Lapidar o magistério de Gilmar Mendes, ao qual aduzimos a intelecção de que a delimitação do conteúdo específico ou pelo menos de seu conteúdo mínimo perpassa necessariamente pela análise do conceito de núcleo essencial dos direitos fundamentais, razão pela qual vamos em seguida analisá-lo ainda que perfunctoriamente.

Pacificou-se na melhor doutrina a existência de um núcleo essencial dos direitos fundamentais, cuja significação aponta para uma região normativa inexpugnável, insusceptível de qualquer invasão, seja pelo legislador (elemento responsável pela criação do texto da norma), seja pelo aplicador do Direito (elemento responsável pela criação da norma concretizada). Assim, a identificação de um conteúdo mínimo dos direitos fundamentais atua como um "limite dos limites", tanto para a criação, como para a aplicação do Direito.

Já na linha jurisprudencial, cumpre destacar, mais uma vez, a construção pretoriana do eminente Ministro Gilmar Mendes:

\footnotetext{
"Alguns ordenamentos constitucionais consagram a expressa proteção do núcleo essencial, como se lê no art. 19, II, da Lei Fundamental alemã de 1949, na Constituição Portuguesa de 1976 (art. 18, III) e na Constituição Espanhola de 1978 (art. 53, no 1). Em outros sistemas, como o norte-americano, cogita-se, igualmente, da existência de um núcleo essencial de direitos individuais. (...) A Lei Fundamental de Bonn declarou expressamente a vinculação do legislador aos direitos fundamentais (LF, art. $\left.1^{\circ}, \mathrm{III}\right)$, estabelecendo diversos graus de intervenção legislativa no âmbito de proteção desses direitos. No art. 19, II, consagrou-se, por seu turno, a proteção do núcleo essencial (In keinem Falle darf ein Grundrecht in seinem Wesengehalt angestatet werden). (...) Na mesma linha, a Constituição Portuguesa e a Constituição Espanhola contêm dispositivos que limitam a atuação do legislador na restrição ou conformação dos direitos fundamentais." (Cf. Constituição portuguesa de 1976, art.18, $n^{\circ} 3$ e Constituição Espanhola de 1978 , art. $\left.53, n^{\circ} 1\right)^{6}$
}

6 HC 85.687/RS, 15/05/2005. 
É com tal tipo de intelecção em mente que se vai em seguida analisar uma possível forma de construir dogmaticamente o núcleo essencial do princípio federativo, mesclando-se doutrina e jurisprudência para atendimento de tal objetivo.

De plano, é importante explicitar que, neste último segmento temático, pretende-se tão somente investigar como a doutrina e a jurisprudência dos tribunais superiores podem ir paulatinamente construindo dogmaticamente o núcleo essencial do princípio federativo.

No âmbito da teoria geral do Estado, o princípio federativo encontra sua base conceitual na ideia de autonomia dos entes federativos. Como genericamente se diz na doutrina, a diferenciação entre Federação e Confederação reside no fato de que a Federação é a união de estados autônomos, interligados sob o vínculo jurídico de uma Constituição, enquanto que a Confederação é a união de estados soberanos, interligados pelo vínculo contratual de um tratado internacional. Reina, portanto, na Ciência Política, a convicção de que os elementos conceituais do federalismo giram em torno do reconhecimento de unidades federativas dotadas de autonomia.

No entanto, a questão é mais complexa, na medida em que os autores não entram em acordo no fixar traços característicos de um estado federal. Celso Ribeiro Bastos (2004) demonstra que existe uma plêiade de concepções acerca do princípio federativo, que varia desde a ideia de diversidade de leis e várias soberanias secundárias, sob uma soberania comum (Hauriou), perpassando pela noção de dois governos no mesmo território unidos pela impossibilidade de se alterarem as competências sem o consentimento de ambos (Duguit), até a intelecção de três ordens jurídicas, duas parciais (a União e os entes federados) e uma global (a da Constituição, que as domina, delimitando-Ihes a competência e determinando um determinado órgão para fazer cumprir tal repartição de competências) (Kelsen). (BASTOS, 2004, pp. 225-226).

A partir dessas considerações, é possível destacar que são duas as perspectivas pelas quais o núcleo essencial do princípio federativo pode ser aferido: autonomia dos componentes da Federação e repartição de competências dos entes federativos.

Aliás, é importante frisar que essas duas não são absolutamente as únicas perspectivas possíveis, cabendo à doutrina ou ao gênio pragmático 
pretoriano, fixar novas visadas dogmáticas que façam progredir a delimitação do núcleo essencial, não só do princípio federativo, mas de cada um dos direitos constitucionais supergarantidos.

Sem embargo de pensamento contrário, não se pode desvincular a forma federativa de Estado da autonomia dos entes federativos ou da própria repartição de competências ou ainda de outros elementos nucleares do princípio estrutural do federalismo.

Considere a seguinte situação hipotética: o Congresso Nacional aprova uma Emenda Constitucional que suprime o art. 30, inciso I, de nossa Carta Magna, dispositivo constitucional cuja fatispécie normativa autoriza os Municípios a legislarem sobre assuntos de interesse local.

Diante de tal norma constitucional derivada, qual seria a normadecisão adequada para o caso? Deveria tal norma de lei constitucional ser declarada inconstitucional? Deveria o exegeta constitucional fazer migrar sua norma-resultado para o domínio eficacial nuclear negativo?

A nosso juízo, acreditamos que sim, porque tal emenda violou a impenetrabilidade do conteúdo mínimo da forma federativa do Estado Brasileiro, uma vez que comprometeu gravemente a repartição horizontal de competências dos entes federativos, elemento nuclear do princípio federativo, enquanto cláusula pétrea.

Com rigor, o problema não está propriamente na repartição constitucional de competências, mas, sim, na forma pela qual ela é posta em prática pela elite política do País. Com rigor, o cerne da questão está na dificuldade em conciliar a descentralização político -administrativa dos entes federativos com os óbices que se antepõem ao desenvolvimento nacional que requerem políticas nacionais para a sua consecução.

Explica-se melhor: o cenário político brasileiro se caracteriza por grandes desigualdades regionais que se potencializam a partir de acentuadas assimetrias na distribuição da renda e da riqueza nacionais. Tais assimetrias demandam políticas nacionais de desenvolvimento unificadas, que, por sua vez, requerem a concentração de competências nas mãos do poder central. Com efeito, não há como ilidir que a mitigação dos desequilíbrios regionais e sociais é mais facilmente obtida a partir de políticas públicas de âmbito nacional. 
Por outro lado, a estrutura democrática do Brasil pós-1988 clama pela descentralização do poder político no espaço como instrumento de resistência a tendências autoritárias de um fictício Estado Federal "centralizador".7

E assim é que entendemos que, no plano geopolítico mais amplo, as políticas públicas sociais devem procurar substituir o vetusto federalismo competitivo - cuja nota maior não é nem a centralização e nem a descentralização, mas, sim, a falta de coordenação entre as três esferas de governo que, sem nenhuma visão estratégica comum, buscam isoladamente desenvolver suas próprias políticas públicas, sendo certo afirmar que a chamada guerra fiscal é seu maior exemplo - pelo federalismo verdadeiramente cooperativo, caracterizado pela existência de políticas públicas compartilhadas entre os três entes federativos, sem laços de hierarquização ou de autoridade. ${ }^{8}$

Nesse mister, não vislumbramos nenhuma incongruência na repartição feita pela Carta Magna ao estabelecer competências administrativas comuns para a União, estados e municípios nas áreas de saúde, assistência social, educação, cultura, habitação e saneamento, meio ambiente, proteção do patrimônio histórico; combate à pobreza e integração social dos setores desfavorecidos e educação para o trânsito, bem como competências legislativas concorrentes aos governos federal e estaduais em rol amplo de assuntos que variam desde a proteção ao meio ambiente e aos recursos naturais até a conservação do patrimônio cultural, artístico e histórico, perpassando pela proteção à infância, à adolescência e aos portadores de deficiências.

Em suma, a dinâmica de organização do poder no espaço necessita agregar aos padrões de interação intergovernamental das unidades

\footnotetext{
7 Autores há que discordam de tal tipo de intelecção. A professora Iná Castro da UFRJ, por exemplo, entende que: "há diferentes graus de centralização (unitarismo) e de descentralização (federalismo) que variam no tempo e no espaço, ou seja, não há um modelo rígido aplicável a todos os países. Além disso, não há nenhuma relação direta entre centralização e autoritarismo ou descentralização e democracia, como a história do Brasil pode fazer crer. A França, por exemplo, é historicamente centralizada e manteve esta condição mesmo sob as regras da democracia moderna, e, da mesma forma, os Estados Unidos são historicamente descentralizados - com um bem nítido federalismo - e democráticos; a Alemanha, no entanto, permaneceu federal, mesmo sob o regime nazista. Portanto, "é a ação resultante dos interesses e dos conflitos que se territorializam e modelam o território, que expressa as características da sociedade e das forças políticas no seu interior". (CASTRO, 2005, p. 131). 8 Outro grande exemplo deste nóxio federalismo competitivo é o caso da saúde antes da implantação do Sistema Único de Saúde (SUS) onde em um mesmo município, tanto a União, quanto o Estado e o próprio governo local desenvolviam redes hospitalares próprias e sem articulação entre si.
} 
político-administrativas do País, elementos sinérgicos de cooperação e de concessões mútuas. A articulação política do espaço público depende de grandes estratégias de desenvolvimento, capazes de sinalizar direções bem definidas em termos de aplicação das políticas públicas. A operacionalização desses grandes conceitos estratégicos deve ser feita através da cooperação entre os entes federativos (no plano vertical) e da sociedade como um todo (no plano horizontal).

Infelizmente, no Brasil, notadamente, nas ciências jurídico-sociais, a preocupação teórica com a dimensão geopolítica dos direitos humanos não tem nenhuma tradição. Somente, recentemente, com a visibilidade que o fenômeno da judicialização da política vem ganhando, é que o Direito Constitucional começa a investigar a questão da legitimidade dos atores institucionais na fixação de políticas públicas. Contudo, há um grande atraso a suplantar e cujas raízes se encontram nas mais diversas áreas do conhecimento científico (na economia, nas relações internacionais, na ciência política, na geopolítica etc.). Com efeito, a Academia Brasileira não consegue cruzar as fronteiras disciplinares, isolando-se, comodamente, em suas respectivas áreas epistemológicas.

Urge, pois, ao jurista brasileiro do século XXI a tomada de consciência do agravamento dos problemas brasileiros que emergem em parte do próprio ordenamento jurídico pátrio. O reconhecimento da tibieza política com que os direitos fundamentais de segunda dimensão vêm sendo tratados pela classe política é, sim, tema da agenda do Poder Judiciário. É nesse sentido que o Direito Constitucional precisa avançar, buscando, paulatinamente, construir dogmaticamente o núcleo essencial dos direitos constitucionais do cidadão brasileiro. Essa tomada de consciência do jurista hodierno é, por sua vez, um grande desafio notadamente ante a fragmentação do edifício epistemológico brasileiro, que se torna cada vez mais nítida diante do processo irreversível de globalização das relações econômicas, sociais e culturais. Correntes contraditórias permeiam o imaginário do jurista contemporâneo, cujo eixo epistemológico varia em torno de uma ideologia dual que polariza o debate acadêmico-científico no binômio: democracia liberal versus social democracia, livre iniciativa versus valor social do trabalho.

E assim é que não se pode ilidir, por exemplo, a perspectiva dialética que coloca, no caso brasileiro, de um lado a necessidade de avanços significativos do federalismo e do municipalismo, e, do outro, a necessidade da liberalização da economia e da integração internacional. Nesse 
contexto, a distribuição espacial do poder entre os entes federativos é tema prioritário das agendas científica, jurídica e política.

\section{CONCLUSÃO}

Conforme afirmado na introdução deste artigo, o princípio federativo ainda carece de grande desenvolvimento dogmático.

Pela sistematização efetuada, foi possível identificar a influência da matriz teórico-conceitual estadunidense sobre o Direito pátrio. Nesse passo, constatou-se que desvios do federalismo centrífugo brasileiro se fazem sentir até hoje, como, por exemplo, o alto grau de concentração de atribuições e competências nas mãos do poder central, em detrimento de uma maior descentralização de viés democrático. Com efeito, verificou-se que forças centrípetas levaram à formação da federação estadunidense e cujo consectário maior é a grande autonomia dos entes federativos subnacionais, que podem legislar, inter alia, sobre Direito Penal, cominando inclusive a pena de morte. No Brasil, a história do pacto federativo foi completamente diferente, pois não havia estados soberanos, mas, sim províncias submetidas ao controle do poder central, o que explica indubitavelmente nossa tendência de concentrar competências na órbita do Governo Federal.

Em um segundo momento analítico, investigamos a trajetória de valorização política da esfera municipal dentro da tridimensionalidade federativa brasileira. Com efeito, restou patente que a ascensão do município dentro da estrutura federalista é um dos principais alicerces da democracia e da cidadania. Nesse diapasão, verificamos que o poder municipal foi erigido à categoria de ente federativo, caso ímpar dentro do federalismo mundial, ganhando, portanto, status de entidade político-administrativa com personalidade jurídica de Direito Público, com governo próprio e competência normativa constitucional.

Para além disso, na reestruturação do pacto federativo feito pela Constituição de 1988, o município foi o principal beneficiário da descentralização de poder político no espaço, principalmente, na esfera tributária e em virtude da ampliação das transferências constitucionais da União e dos estados-membros. Em suma, além de ter-se transformado em ente federativo, o poder municipal foi aquinhoado com competências e atribuições na área social que lhe projeta como baluarte do impulso descentralizador da estrutura federalista pátria, caso suplante o dogma de clientelismo e populismo que circunscreve sua imagem. 
Finalmente, há a questão da construção dogmática do núcleo essencial do princípio federativo, tema instigante e desafiador que coloca no ombro da doutrina e da jurisprudência significativo fardo hermenêutico. Conforme visto ao longo do trabalho, a delimitação do alcance e conteúdo do pacto federal requer análise percuciente que se projeta sobre seus elementos nucleares. Quadra, pois, aqui destacar a intelecção de que a verificação da impenetrabilidade do núcleo essencial do princípio federativo exige a identificação das suas relações de interdependência dentro do sistema constitucional como um todo.

Nessa linha de entendimento, constatamos que a lesão a preceito fundamental não se configura apenas quando se verificar possível afronta ao princípio federativo, mas também a disposições constitucionais que confiram densidade normativa ou significado específico ao pacto federativo, notadamente a autonomia dos governos subnacionais e a repartição constitucional de competências.

\section{REFERÊNCIAS}

BASTOS, Celso Ribeiro. Curso de teoria do estado e ciência política. 6 . ed. São Paulo: Celso Bastos Editora, 2004.

CASTRO, Iná Elias de. Geografia e política: território, escalas de ação e instituições. Rio de Janeiro: Bertrand Brasil, 2005.

MOREIRA, Lia Sammia Souza. Federalismo ou centralização: o caso brasileiro. Rio de Janeiro: Biblioteca da Escola Superior de Guerra, Departamento de Estudos, MO 02 DAP, 2002, p. 49.

SILVA, José Afonso da Silva. Curso de Direito Constitucional. 14. ed. São Paulo: Ed. Malheiros, 1997.

VON RONDOW, Cristian de Sales. Brasil: um país a caminho de uma Federação justa e equilibrada. Jus, [S.I], nov. 2002. Disponível em: <http://jus2.uol.com.br/doutrina/texto.asp?id=3508 >. Acesso em: 29 abr. 2006.

ZIMMERMANN, Augusto. Teoria geral do federalismo democrático. 2. ed. Rio de Janeiro: Renovar, 2005. 